\title{
KAJIAN SENGON (Paraserianthes falcataria) SEBAGAI POHON BERNILAI EKONOMI DAN LINGKUNGAN
}

\author{
Study on Sengon (Paraserianthes falcataria) as Economical and Ecological Tree
}

Heru Dwi R., Susi. A, dan/and Ragil. B.W.M.P

Balai Penelitian Kehutanan Solo

Jl. A. Yani, PO. BOX 295 Sukoharjo Pabelan, Solo 57102

Naskah masuk: 14 Maret 2008 ; Naskah diterima: 9 Februari 2009

\begin{abstract}
Community forests has almost cover the land area of Banyumas and Wonosobo Sub-Province and plays an important role in community economical and maintaining global environment, such as controlling flood, desertification process, and sequestration and fixation of $\mathrm{CO}_{2}$. The existing forest was decreasing due to slash and burn activities, over forest felling for fuel wood and commercial timber, conversion of forest land to other uses. Our world is now opening to adversity of global warming. It is believed that most of $\mathrm{CO}_{2}$ and other green house gases were release from economics activities formed a layer surrounding world atmosphere, stopped solar energy, and caused a raise average temperature. Climate change caused by global warming has overcome to more intent natural disaster in some parts of the world as before. Concerning this situation, BPK-Solo have conducted a study to collect and analyze some data to know the growth and yield and quantify the fixation of carbon content in sengon (Paraserianthes falcataria) stands biomass as one favorite species in developing industrial plantation forest and community forest. The study was located at sengon community forest in Banyumas and Wonosobo Sub Province Central Java. The research deals with the observation of the current condition and does not employ a treatment. The research methodology used to quantify carbon sequestration in the plant biomass was using IPCC approximation guidelines (in Retnowati, 1998), and for the growth yield are by measuring the high and diameter tree, and further by mathematical equation analysis.The results of the study showed that the correlation equations between stand/plant age and diameter, total dry weight biomass and diameter, also carbon content and diameter give high value of determination coefficient. It means that those equations could be use to estimate the carbon content of teak stand/plant.
\end{abstract}

Key words: Paraserianthes falcataria, community forest, growth-yield, quantification, carbon content

\begin{abstract}
ABSTRAK
Hutan rakyat sengon hampir menutupi sebagian wilayah Kabupaten Wonosobo dan Banyumas dan memainkan peran yang penting dalam perekonomian masyarakat serta di dalam memelihara lingkungan global, seperti pencegahan banjir, pengendalian proses pemadang-pasiran dan penyerapan serta fiksasi $\mathrm{CO}_{2}$. Hutan alam telah semakin berkurang, yang disebabkan oleh kegiatan tebas dan bakar, illegal logging, penebangan pohon secara berlebihan serta konversi dari tanah-tanah hutan menjadi tanahtanah pertanian. Hutan di satu sisi sebagai penjerap emisi karbon di sisi lain juga dapat menghasilkan/menyumbang emisi karbon di udara. Dengan makin berkurangnya hutan alam dari tahun ke tahun, akan menyebabkan berkurangnya pasokan bahan baku kayu bagi industri perkayuan yang ada selain itu juga dapat meningkatkan emisi karbon di udara apabila pembakaran hutan selalu dilakukan dalam aktivitas manusia baik di dalam ataupun di luar kawasan hutan. Berkurangnya luasan hutan juga
\end{abstract}


dapat menyebabkan semakin menurunnya kualitas lingkungan hidup yang disebabkan hilangnya vegetasi pepohonan sebagai penjerap emisi karbon udara. Permasalahan di atas sebenarnya dapat di atasi apabila upaya penanaman pohon-pohonan dalam gerakan reboisasi hutan dan lahan, hutan tanaman industri dan hutan rakyat dapat berhasil dengan baik sehingga dapat memberikan konstribusi baik terhadap perekonomian maupun lingkungan. Memahami situasi demikian, BPK Solo melakukan penelitian untuk mengumpulkan dan menganalisa berbagai data guna mengetahui pertumbuhan sengon serta mengkuantifikasikan kandungan karbon dalam biomasa tegakan sengon (Paraserianthes falcataria) sebagai salah satu jenis unggulan dalam pembangunan hutan tanaman industri dan hutan rakyat. Dalam penelitian ini, lokasi yang dipilih adalah Kabupaten Wonosobo dan Banyumas. Penelitian yang dilakukan merupakan pengamatan (observasi) terhadap kondisi yang ada dan tidak melakukan perlakuan. Metode yang digunakan untuk mengetahui rosot karbon dalam tanaman adalah dengan pendekatan IPCC Guidelines (1995) dalam Retnowati (1998). Pertumbuhan sengon didekati dengan melakukan pengukuran diameter dan tinggi tanaman, yang selanjutnya dianalisis ke dalam suatu persamaan matematika. Hasil penelitian ini menunjukkan bahwa persamaan hubungan keeratan (determinasi) antara umur tegakan/tanaman dengan diameter, volume dengan diameter, berat kering total biomassa dengan diameter dan kandungan karbon dengan diameter, memberikan nilai koefisien determinasi yang cukup tinggi sampai tinggi, ini berarti, persamaan-persamaan tersebut dapat digunakan untuk mengestimasi kandungan karbon tegakan/tanaman jati.

\section{Kata kunci : Sengon (Paraserianthes falcataria), hutan rakyat, growth and yield, kuantifikasi, kandungan karbon}

\section{PENDAHULUAN}

Nilai kayu sengon (Paraserianthes falcataria (L) Nielsen) bagi sebagian besar penduduk yang bermukim di wilayah Kabupaten Wonosobo memiliki peran penting, karena hasilnya mampu memberikan konstribusi finansial dalam menunjang pendapatan keluarga petani. Oleh karena peranannya yang positif tersebut, diduga lebih dari $50 \%$ jumlah kecamatan yang berada di wilayah Kabupaten Wonosobo merupakan daerah sentra produksi kayu sengon rakyat (Andayani, 2003).

Sengon sebagai komoditi ekonomi dalam hutan rakyat yang dianggap cukup prospektif dan menjanjikan dari aspek finansial, pada kenyataannya masih terkendala oleh permasalahan produktivitas. Pertumbuhan penduduk dan tuntutan kualitas serta kuantitas pangan, papan dan energi telah menyebabkan manusia memanfaatkan sumber daya alam melebihi kapasitasnya. Peningkatan kebutuhan hidup tersebut tercermin dari perubahan antara lain meliputi peningkatan penggunaan energi dari bahan bakar fosil maupun perubahan penggunaan lahan. Kedua hal tersebut dapat menyebabkan peningkatan panas global yang selanjutnya menyebabkan perubahan iklim global, serta terjadinya peningkatan luasan lahan kritis.

Indonesia sangat berpotensi menjadi negara penyerap emisi karbon karena Indonesia mempunyai kawasan hutan tropis yang luas, dimana vegetasi hutan merupakan salah satu faktor yang dapat menurunkan akumulasi $\mathrm{CO}_{2}$ di atmosfer melalui penjerapan oleh vegetasi. Potensi tersebut bahkan dapat lebih ditingkatkan dengan upaya penanaman jenis pada hutan yang rusak yang tersebar luas. Bila lahan yang terdegradasi tersebut dapat direhabilitasi dengan metode konservasi yang tepat bukan tidak mungkin areal tersebut dapat digunakan sebagai media pengurangan emisi dengan membangun carbon sink yang baru, yaitu melalui aktivitas pembuatan hutan tanaman dan atau hutan rakyat dengan metode pengelolaan yang tepat.

Sehubungan dengan hal tersebut di atas, maka penelitian ini selain bertujuan untuk mendapatkan suatu informasi mengenai growth and yield juga mengkuantifikasikan kandungan karbon pada tegakan sengon (Paraserianthes falcataria) sebagai salah satu jenis unggulan dalam pembangunan hutan tanaman industri dan hutan rakyat. 


\section{BAHAN DAN METODE}

\section{A. Waktu dan Lokasi}

Penelitian dilaksanakan pada tahun 2005-2006, dengan lokasi penelitian adalah hutan rakyat di Kabupaten Wonosobo dan Banyumas, Provinsi Jawa Tengah .

\section{B. Bahan dan Peralatan}

Bahan yang digunakan adalah tegakan sengon, sampel biomassa, dan perlengkapan lapangan. Peralatan lapangan yang digunakan adalah haga meter, meteran, GPS dan sebagainya.

\section{Rancangan Penelitian}

\section{Jenis Penelitian}

Penelitian yang dilakukan merupakan pengamatan (observasi) terhadap kondisi yang ada dan tidak melakukan perlakuan.

\section{Rancangan Penelitian}

Metode yang digunakan untuk mengetahui rosot karbon dalam tanaman adalah dengan pendekatan IPCC Guidelines (1995) dalam Retnowati (1998). Dalam penelitian ini diasumsikan bahwa jumlah karbon yang dapat diserap dan disimpan oleh tanaman sama dengan jumlah karbon yang terdapat dalam biomassa tanaman tersebut.

Penelitian growth and yield ini dilaksanakan melalui pengukuran parameter diameter dan tinggi pohon, selanjutnya hasil pengukuran diolah secara deskriptif statistik.

\section{Parameter}

Parameter biofisik yang dikumpulkan meliputi :

- Tinggi dan diameter tanaman setinggi dada (dbh), volume tegakan

- Berat basah dan berat kering biomasa tanaman

- Kandungan karbon organik dalam biomasa tegakan, tanah dan sifat-sifat lahan (kedalaman tanah, tekstur, kedalaman perakaran, drainase, lereng, $\mathrm{pH}$ ).

\section{Pengambilan data}

Untuk mengetahui kuantitas karbon dalam biomasa tegakan/tanaman, diperoleh melalui tahapan sebagai berikut :

- Estimasi volume tegakan, dilakukan dengan mengukur tinggi dan diameter tegakan (dbh), pengambilan contoh yang diukur 1 - $5 \%$ dari populasi

- Untuk mengetahui berat basah batang, cabang dan ranting, daun (tajuk) dan akar ditimbang di lapangan

- Untuk mengetahui berat kering dan kandungan karbon pada batang, dilakukan dengan cara destructive sampling, yaitu dengan melakukan penebangan. Pohon yang ditebang mewakili diameter besar, sedang dan kecil (Morikawa et al., 2001). Setiap pohon terpilih akan diambil contoh batang setebal $5 \mathrm{~cm}$ pada segmen batang 0-30 cm, 30-230 cm, 230-430 cm, 430-630 cm, dan seterusnya dari panjang batang

- Contoh cabang dan ranting diambil pada cabang bagian bawah, tengah dan atas

- Contoh daun diambil pada bagian bawah, tengah dan atas

- Akar dibongkar dan diambil serta ditimbang secara keseluruhan, baru kemudian diambil contohnya 
- Berat kering biomasa diperoleh setelah contoh dikeringkan di oven selama 48 jam pada suhu $60^{\circ} \mathrm{C}$. Selanjutnya contoh tersebut dianalisis kandungan karbonnya.

\section{Pengolahan dan Analisis Data}

a. Biomassa tegakan dapat diestimasi dari persamaan allometrik (antara dbh dengan total berat kering (BKT) sebagai berikut (Diana et al .,2003)

$$
\begin{aligned}
& \left.\mathrm{BKT}=\mathrm{a}\left(\mathrm{dbh}^{2}\right)^{\mathrm{b}} \quad \text { (persamaan } 1\right) \\
& \mathrm{a} \text { dan b koefisien }
\end{aligned}
$$

b. Kuantifikasi pengurangan $\mathrm{CO}_{2}$ udara oleh tanaman diperoleh dari konversi karbon dalam biomassa tanaman dengan rumus (Morikawa, 2003) :

$$
\mathrm{CO}_{2}=44 / 12 \times \mathrm{C} \quad(\text { persamaan 2). }
$$

\section{HASIL DAN PEMBAHASAN}

\section{A. Hasil Pengukuran}

Dari pengukuran di lapangan pada beberapa umur tegakan sengon, dan analisa laboratorium contoh biomassa diperoleh hasil seperti pada Tabel 1 .

Tabel (Table) 1. Hasil pengukuran tegakan dan analisa biomassa sengon (Paraserianthes falcataria) pada berbagai umur tegakan (Result of stand measurement, and biomass analysis on several stand ages of sengon (Paraserianthes falcataria))

\begin{tabular}{|c|c|c|c|c|c|}
\hline No. & $\begin{array}{c}\text { Umur } \\
(\text { tahun }) \\
(\text { age }(\text { year }))\end{array}$ & $\begin{array}{c}\text { Diameter } \\
\text { rata-rata } \\
(\text { diameter average }) \\
(\mathrm{cm})\end{array}$ & $\begin{array}{c}\text { Berat kering total/pohon } \\
(\text { total dry weight/tree }) \\
(\mathrm{kg})\end{array}$ & $\begin{array}{c}\text { \% Karbon } \\
(\% \text { carbon })\end{array}$ & $\begin{array}{c}\text { Kandungan karbon } \\
(\text { carbon content }) \\
(\mathrm{kg} / \mathrm{phn})\end{array}$ \\
\hline 1. & 2 & 6 & 16,38 & 56,96 & 9,33 \\
\hline 2. & 3 & 9 & 17,14 & 62,05 & 10,64 \\
\hline 3. & 4 & 10 & 19,76 & 58,81 & 11,62 \\
\hline 4. & 5 & 13 & 37,84 & 64,83 & 24,53 \\
\hline 5 & 6 & 15 & 76,58 & 64,95 & 49,73 \\
\hline 6 & 8 & 20 & 120,28 & 65,65 & 78,93 \\
\hline
\end{tabular}

Keterangan (Remarks) : \% Karbon $=$ Jumlah karbon dalam biomassa dalam persen

$(\%$ Carbon $=$ percentage of carbon content in biomass $)$

\section{B. Estimasi Growth and Yield, Kandungan Karbon dan Pengurangan Emisi $\mathrm{CO}_{2}$ Udara}

Untuk memperoleh gambaran growth and yield serta kandungan karbon dalam tegakan sengon dengan mengoptimalkan data yang ada, yang harus dilakukan adalah :

1. Membuat suatu persamaan (equation) hubungan antara umur tanaman dengan diameter tanaman, sehingga akan diperoleh satu estimasi nilai/besaran diameter pada berbagai umur tegakan. Dari tahap ini diperoleh persamaan sebagai berikut : 
$\mathrm{Y}=4,6338 \mathrm{e}^{0,1913 \mathrm{x}}$

dengan Nilai $R^{2}=0,9722$

dimana $\mathrm{X}$ adalah umur, $\mathrm{Y}$ adalah diameter tanaman dan e adalah bilangan pokok logaritma natural $=2,7183$

2. Membuat suatu persamaan (equation) hubungan antara diameter rata-rata dengan volume/isi pohon, sehingga akan diperoleh satu estimasi nilai/besaran volume/isi pada berbagai diameter. Dari tahap ini diperoleh persamaan sebagai berikut :

$$
\begin{aligned}
& Y=0,0063 e^{0,2354 x} \\
& \text { dengan Nilai } \quad R^{2}=0,8838
\end{aligned}
$$

dimana $\mathrm{X}$ adalah diameter, $\mathrm{Y}$ adalah volume tanaman dan e adalah bilangan pokok logaritma natural $=2,7183$

3. Biomassa tegakan dapat diestimasi dari persamaan allometrik (antara dbh dengan total berat kering) (BKT) sebagai berikut,

$$
\mathrm{BKT}=\mathrm{a}\left(\mathrm{dbh}^{2}\right)^{\mathrm{b}}
$$

dimana : a dan b adalah koefisien

Dari persamaan di atas diperoleh suatu persamaan riil sebagai berikut :

$$
\begin{aligned}
\text { BKT }= & 0.3518 \mathrm{X}^{0,9497} \\
\text { dimana } & \mathrm{X} \text { adalah } \mathrm{dbh}^{2}, \\
\text { dengan Nilai } & \mathrm{R}^{2}=0,8917
\end{aligned}
$$

4. Kandungan karbon dalam tegakan dapat diestimasi dari persamaan allometrik (antara dbh dengan total karbon sebagai berikut,

$$
\begin{aligned}
& \mathrm{C}=\mathrm{a}\left(\mathrm{dbh}^{2}\right)^{\mathrm{b}} \\
& \text { dimana }: \mathrm{a} \text { dan } \mathrm{b} \text { adalah koefisien }
\end{aligned}
$$

Dari persamaan di atas diperoleh suatu persamaan riil sebagai berikut :

$$
\begin{aligned}
\mathrm{Y}=0.1129 \mathrm{X}^{1.0802} \\
\text { dimana } \quad \mathrm{X} \text { adalah } \mathrm{dbh}^{2}, \\
\text { dengan Nilai } \quad \mathrm{R}^{2}=0,9309
\end{aligned}
$$

Dari ke empat persamaan (equation) di atas terlihat bahwa ketiga persamaan tersebut memiliki koefisien determinasi yang cukup tinggi sampai tinggi. Hal ini dapat diartikan bahwa ke empat persamaan tersebut dapat digunakan untuk menduga/mengestimasi peubah bebas yang diinginkan dengan cukup akurat. Hasil estimasi dari persamaan hubungan antara umur pohon dengan diameter (dbh) pohon, persamaan hubungan antara volume/isi dan diameter (dbh), persamaan hubungan antara dimeter (dbh) dengan total berat kering biomasa, dan persamaan hubungan antara diameter (dbh) dengan kandungan karbon disajikan dalam Tabel 2. 
Tabel (Table) 2. Hasil estimasi diameter, volume tegakan, berat kering dan kandungan karbon menggunakan persamaan-persamaan (Estimation on diameter, stand volume, total dry weight and carbon content of the equations) $\mathrm{Y}=4,6338 \mathrm{e}^{0,1913 \mathrm{x}}, \mathrm{Y}=0,0063 \mathrm{e}^{0,2354 \mathrm{x}}$, $\mathrm{Y}=0.3518 \mathrm{X}^{0,9497}, \mathrm{Y}=0.1129 \mathrm{X}^{1.0802}$

\begin{tabular}{|c|c|c|c|c|c|}
\hline No & $\begin{array}{c}\text { Umur } \\
(\text { ages }) \\
(\text { tahun/year })\end{array}$ & $\begin{array}{c}\text { Diameter rata-rata } \\
(\text { diameter average })\end{array}$ & $\begin{array}{c}\text { Volume } \\
(\mathrm{cm})\end{array}$ & $\begin{array}{c}\text { Berat kering total } \\
(\text { total dry weight }) \\
(\mathrm{kg})\end{array}$ & $\begin{array}{c}\text { Kandungan karbon } \\
(\text { carbon content }) \\
(\mathrm{kg})\end{array}$ \\
\hline 1 & 1 & 6 & 0,03 & 10,58 & 5,42 \\
\hline 2 & 2 & 7 & 0,03 & 14,17 & 7,56 \\
\hline 3 & 3 & 8 & 0,04 & 18,27 & 10,09 \\
\hline 4 & 4 & 10 & 0,07 & 27,91 & 16,33 \\
\hline 5 & 5 & 12 & 0,11 & 39,45 & 24,22 \\
\hline 6 & 6 & 15 & 0,22 & 45,93 & 39,22 \\
\hline 7 & 7 & 18 & 0,44 & 85,22 & 58,15 \\
\hline 8 & 8 & 21 & 0,88 & 114,21 & 81,14 \\
\hline
\end{tabular}

Dari hasil di atas dapat diestimasikan potensi kayu sengon dalam Tabel 3, apabila diasumsikan per hektar terdapat 1250 batang.

Tabel (Table) 3. Hasil estimasi potensi volume tegakan hutan rakyat per umur tanaman (Estimation of stand volume of community forest at each stand ages)

\begin{tabular}{|c|c|c|c|c|}
\hline No & $\begin{array}{c}\text { Umur } \\
(\text { ages })\end{array}$ & $\begin{array}{c}\text { Diameter rata-rata } \\
(\text { diameter average }) \\
(\mathrm{cm})\end{array}$ & $\begin{array}{c}\text { Volume/batang } \\
(\text { volume/tree }) \\
\left(\mathrm{m}^{3}\right)\end{array}$ & $\begin{array}{c}\text { Volume/ha } \\
(\text { volume/hectare }) \\
\left(\mathrm{m}^{3}\right)\end{array}$ \\
\hline 1 & 1 & 6 & 0,03 & 37,5 \\
\hline 2 & 2 & 7 & 0,03 & 37,5 \\
\hline 3 & 3 & 8 & 0,04 & 50 \\
\hline 4 & 4 & 10 & 0,07 & 87,5 \\
\hline 5 & 5 & 12 & 0,11 & 2737,5 \\
\hline 6 & 6 & 15 & 0,22 & 275 \\
\hline
\end{tabular}

Dari tabel di atas terlihat bahwa sengon dapat memberikan nilai ekonomi yang cukup besar, apabila harga sengon dengan diameter rata-rata $15 \mathrm{~cm}$ adalah $\pm \mathrm{Rp} 150.000$,- maka dalam enam tahun masyarakat akan mendapatkan \pm Rp. 41.250.000,- atau setiap bulan petani hutan rakyat akan menerima penghasilan tambahan sebesar \pm Rp. 600.000 ,-. Selain itu selama enam tahun masyarakat juga akan memperoleh keuntungan tambahan (intangible benefit) yaitu lingkungan yang sehat. Keuntungan tambahan tersebut dapat dilihat pada Tabel 4.

Dari hasil estimasi pada Tabel 2 dan dengan menggunakan rumus persamaan 2 akan diperoleh pengurangan emisi $\mathrm{CO}_{2}$ udara seperti pada Tabel 4 berikut ini. 
Tabel (Table) 4. Estimasi pengurangan emisi $\mathrm{CO}_{2}$ udara oleh tegakan sengon pada berbagai kelas umur (Estimation reduction of $\mathrm{CO}_{2}$ by sengon stand on several age classes)

\begin{tabular}{|c|c|c|c|}
\hline $\begin{array}{c}\text { Umur } \\
\text { (age) }\end{array}$ & $\begin{array}{c}\text { Jumlah pohon/ha } \\
\text { (number of trees/ha) }\end{array}$ & $\begin{array}{c}\text { Kandungan karbon } \\
\text { (carbon contain) } \\
\text { (ton/ha) }\end{array}$ & $\begin{array}{c}\text { Pengurangan } \mathrm{CO}_{2} \text { udara } \\
\left(\mathrm{CO}_{2} \text { reduction) }\right. \\
\text { (ton/ha) }\end{array}$ \\
\hline 1 & 1250 & 6,775 & $24,841,67$ \\
\hline 2 & 1250 & 9,450 & 34,650 \\
\hline 3 & 1250 & $12,612,5$ & $46,245,83$ \\
\hline 4 & 1250 & $20,412,5$ & $74,845,83$ \\
\hline 5 & 1250 & 30,275 & $111,008,3$ \\
\hline 6 & 1250 & 49,025 & $266,758,3$ \\
\hline 7 & 1250 & $72,687,5$ & $371,891,7$ \\
\hline 8 & 1250 & 101,425 & \\
\hline
\end{tabular}

Pada Tabel 4 terlihat bahwa semakin tua umur tegakan sengon telah menyebabkan peningkatan pengurangan emisi gas karbon yaitu dari 24,841 ton/ha pada umur 1 tahun meningkat menjadi 371,891 ton/ha pada umur 8 tahun.

\section{KESIMPULAN DAN SARAN}

\section{A. Kesimpulan}

1. Persamaan hubungan yang dibuat untuk mengestimasi nilai produksi dan lingkungan semua mempunyai nilai determinasi yang cukup tinggi sampai tinggi, sehingga persamaan tersebut dapat digunakan untuk mengestimasi peubah bebas yang diinginkan dengan cukup akurat.

2. Sengon sebagai vegetasi hutan cukup prospektif dalam upaya peningkatan pendapatan masyarakat pedesaan, juga mempunyai manfaat lingkungan dalam hal pengurangan emisi $\mathrm{CO}_{2}$ udara yang baik.

\section{B. Saran}

Perlu dilakukan kajian kuantifikasi menggunakan metode selain metode destruktif sehingga kesulitan dalam penebangan dan kendala harga kayu dapat dieliminir.

\section{DAFTAR PUSTAKA}

Andayani, W. 2003. Efisiensi Pemasaran Kayu Sengon Rakyat di Daerah Sentra Produksi Kabupaten Wonosobo. Jurnal Hutan Rakyat, Pusat Kajian Hutan Rakyat, Fakultas Kehutanan UGM.

Diana, R., D. Hadriyanto, M. Hiratsuka, T. Toma, Y, Morikawa, 2003. Carbon Stocks of Fast Growing Tree Species and Baselines after Forest Fire in East Kalimantan, Indonesia. International Symposium on forest carbon sequestration and monitoring. 12-13 September 2003, Balikpapan,. Universitas Mulawarman.

Foley, G. 1993. Pemanasan Global. Yayasan Obor, Jakarta. 
Handoko, A. Sugandhy dan Gunardi. 1996. Inventory of Greenhouse Gases Emissions and Sinks in Indonesia. The State Ministry of Environment Republic Of Indonesia.

Morikawa, Y. 2003. Manual of Biomass Measurements in Plantation and Regenerated Vegetation. Japan International Forestry Promotion and Cooperation Center (JIFPRO) - Japan Overseas Plantation Center of Pulpwood (JOPP). Tokyo

Morikawa, Y., H. Inoue, M. Yamada, D. Hadriyanto, R. Diana, Marjenah, and M. Fatawi, 2001. Carbon Accumulation of Man-made Forest. In Monsoon Asia in relation to CDM. Proc. Inter. Workshop BIO-REFOR Tokyo : pp43-51

Murdiyarso, D. 1999. Perlindungan Atmosfer melalui Perdagangan Karbon : Paradigma Baru dalam Sektor Kehutanan. Orasi Ilmiah Guru Besar Tetap Ilmu Atmosfer, Fak. Matematika dan Ilmu Pengetahuan Alam, IPB, Bogor.

Retnowati, E. 1998. Kontribusi Hutan Tanaman Eucalyptus grandis Maiden sebagai Rosot Karbon di Tapanuli Utara. Bul. Penelitian Hutan. No.611 : 1-10. Pusat Penelitian dan Pengembangan dan Konservasi Alam, Bogor. 